\title{
Detection of Bacteroides fragilis endotoxin in amniotic fluid by counterimmunoelectrophoresis
}

\author{
I. Beckmann ${ }^{1}$, K. de Graaff ${ }^{1}$, F. Meisel-Mikołajczyk ${ }^{2}$ \& H.C.S. Wallenburg ${ }^{1}$ \\ ${ }^{1}$ Department of Obstetrics and Gynecology, Erasmus University Medical School, Rotterdam, The Netherlands \\ ${ }^{2}$ Department of Bacteriology and Immunology, Medical Academy, Warsaw, Poland
}

Accepted 2 May 1994

Key words: B. fragilis, endotoxin, counterimmunoelectrophoresis, ultrafiltration, amniotic fluid

\begin{abstract}
The ability of counter immunoelectrophoresis (CIE) to detect Bacteroides fragilis endotoxin in amniotic fluid in small concentrations was evaluated. A method was developed which, in combination with ultrafiltration, permits detection of $B$. fragilis endotoxin in amniotic fluid in a concentration of $40 \mathrm{ng} / \mathrm{ml}$ or more. The sensitivity threshold was reduced to $2 \mathrm{ng} / \mathrm{ml}$ by using a highly reactive IgG-fraction isolated from rabbit anti-B. fragilis IPL E 323 antiserum.
\end{abstract}

\section{Introduction}

Counterimmunoelectrophoresis (CIE) has been successfully employed for the detection of polysaccharide antigens isolated from various species of the genus Streptococcus, Pneumococcus, Haemophilus and Neisseria in serum (Shackelford et al. 1974; Ingram et al. 1972; Granoff et al. 1977; Shetty et al. 1985), liquor cerebrospinalis (Shackelford et al. 1974; Ingram et al. 1972; Granoff et al. 1977), urine (Shackelford et al. 1974), sputum (El-Refaie \& Dulake 1975; Ericsson et al. 1986) and tears (Powell et al. 1988). Streptococcus $B$ polysaccharide has also been detected in amniotic fluid (Jacobs et al. 1981). The specific detection of lipopolysaccharides (LPS), the endotoxins of gram negative bacteria, by CIE in amniotic fluid has not yet been described.

During our study of the maternal and fetal immuneresponse to $B$. fragilis endotoxin in pregnant guinea pigs (Beckmann et al. 1991) it became necessary to assess in amniotic fluid the presence of $B$. fragilis endotoxin in low concentrations. This present study describes a modified system of CIE for the specific detection of $B$. fragilis endotoxin in small quantities in amniotic fluid.

\section{Material and methods}

B. fragilis endotoxin

Bacteria (B. fragilis IPL E 323) were extracted with phenol/water and the lipopolysaccharide isolated as described by Beckmann et al. (1989).

Antisera

Rabbit antisera against $B$. fragilis IPL E 323 bacteria were prepared as described by Meisel-Mikolajczyk et al. (1981). The antisera $E_{2} 8$ and $E_{2} 9$ were from different rabbits immunized with the same bacterial suspension.

Isolation of $\mathrm{IgG}$ from $\mathrm{B}$. fragilis antiserum

According to the method of McKinney \& Parkinson (1987) rabbit anti $B$. fragilis antiserum was precipitated with n-caprylic acid, cooled to $4^{\circ} \mathrm{C}$ and fractionated with ammonium sulfate (45\% saturation). After stirring for $30 \mathrm{~min}$ the precipitated $\mathrm{IgG}$ was collected by centrifugation at $2000 \mathrm{~g}$ for $20 \mathrm{~min}$. The precipitate was dissolved in a small volume of phosphate buffered saline (PBS) and dialysed at $4^{\circ} \mathrm{C}$ over night against PBS. After heating for $20 \mathrm{~min}$ at $55^{\circ} \mathrm{C}$ the protein 
content of the solution was determined by absorption spectrometry at $260 \mathrm{~nm}$.

$\mathrm{IgG}_{1}$ was isolated from antiserum $\mathrm{E}_{2}(83), \mathrm{IgG}_{2}$ from antiserum $B$. fragilis $\mathrm{E}_{2}(8)$. The sera were obtained by immunization of rabbits with different preparations of bacterial suspensions.

\section{Amniotic fluid}

Amniotic fluid from healthy pregnant guinea pigs was isolated on day 61 of the gestation, centrifuged at $1500 \mathrm{rpm}$, and the clear supernatant stored at $-20^{\circ} \mathrm{C}$ until assay.

\section{Ultrafilters}

Ultrafilters UFC3 LCC00 (Molecular weight (MW) limit MW < $5000 \mathrm{D}$ ) and UFC3 LGCOO (MW limit $\mathrm{MW}<10000 \mathrm{D})$ were from Millipore B.V., Etten-Leur, The Netherlands.

\section{Chemicals}

All chemicals were from Sigma, St. Louis, U.S.A. and Merck, Darmstadt, Germany.

\section{Counterimmunoelectrophoresis (CIE)}

CIE was performed on microscopic slides covered with $2 \mathrm{ml}$ of agarose gel (1\% agarose in Laurell buffer (pH 8.6). After electrophoresis the slides were incubated over night in a humid chamber at $4^{\circ} \mathrm{C}$ in PBS and stained according to the method of Weeke (Weeke 1973) with Coomassie Brilliant Blue G 225. All results were assessed blinded, by an independent investigator.

\section{Grabar-immunoelectrophoresis}

The one-dimensional immunoelectrophoresis on microscopic slides was performed as described by Beckmann et al. (1985).

\section{Ultrafiltration of amniotic fluid}

LPS dissolved in amniotic fluid was kept for $3 \mathrm{~min}$ at $100^{\circ} \mathrm{C}$ and $400 \mu \mathrm{l}$ of the solution were applied to an ultrafilter and centrifuged for $60 \mathrm{~min}$ at $2000 \mathrm{~g}$ and $20^{\circ} \mathrm{C}$. New solution was added, until the original solution remaining in the filter was concentrated ten-
Table 1. Minimal detectable concentration of $B$. fragilis LPS in CIE depending on antibody source.

\begin{tabular}{lcl}
\hline Antibody source & Number of tests & $\begin{array}{l}\text { Detectable } \\
\text { concentrations LPS } \\
(\mu \mathrm{g} / \mathrm{ml})\end{array}$ \\
\hline Antiserum E $_{2}{ }^{8}$ & 15 & $0.31-0.63$ \\
Antiserum E $_{2}{ }^{9}$ & 3 & $0.31-0.63$ \\
IgG-fraction (1) & 3 & $0.02-0.03$ \\
IgG-fraction (2) & 3 & $0.75-1.56$ \\
\hline
\end{tabular}

fold. The volumes of remaining and filtered fluids were measured and kept at $-20^{\circ} \mathrm{C}$ until further testing.

\section{Results}

The optimum sensitivity threshold for the detection of $B$. fragilis LPS with CIE was determined by varying the conditions (quantity of antibody, distance between antigen and antibody reservoirs, field strength and duration of electrophoresis). The final procedure was as follows: On agarose-covered microscopic slides two rows of holes (diameter $3.5 \mathrm{~mm}$ ) with a distance of $3 \mathrm{~mm}$ between rows were applied. B. fragilis LPS, dissolved in PBS (pH 7.4), was diluted 1:2 in amniotic fluid, and $6 \mu$ of each dilution were placed into the holes directed towards the cathode; $8 \mu$ lantiserum were put into the holes directed towards the anode. Controls for amniotic fluid and PBS were included. After electrophoresis for $45 \mathrm{~min}$ at a field strength of $3.2 \mathrm{~V} / \mathrm{cm}$ and $20^{\circ} \mathrm{C}$, the immunoprecipitates were processed as described above. Under these conditions $310-630 \mathrm{ng}$ of $B$. fragilis LPS could be detected.

The detection limit depends on the concentration of antibodies within the antibody source. Table 1 shows the detectable LPS-concentrations after application of different sources of antibodies in the CIE test.

The ultrafiltration of amniotic fluid, containing $B$. fragilis IPL E 323 LPS, was performed with two types of ultrafilters $(5000$ and $10000 \mathrm{D})$, permitting the passage of substances with a molecular weight $\angle 5000 \mathrm{D}$ or $<10000 \mathrm{D}$. The permeability of both filters for the LPS of $B$. fragilis was investigated by Grabar immunoelectrophoresis and CIE of residues and filtrates after ultrafiltration of $500 \mu \mathrm{g}$ LPS dissolved in $1 \mathrm{ml}$ amniotic fluid. Figure 1 shows the results of Grabar immunoelec- 


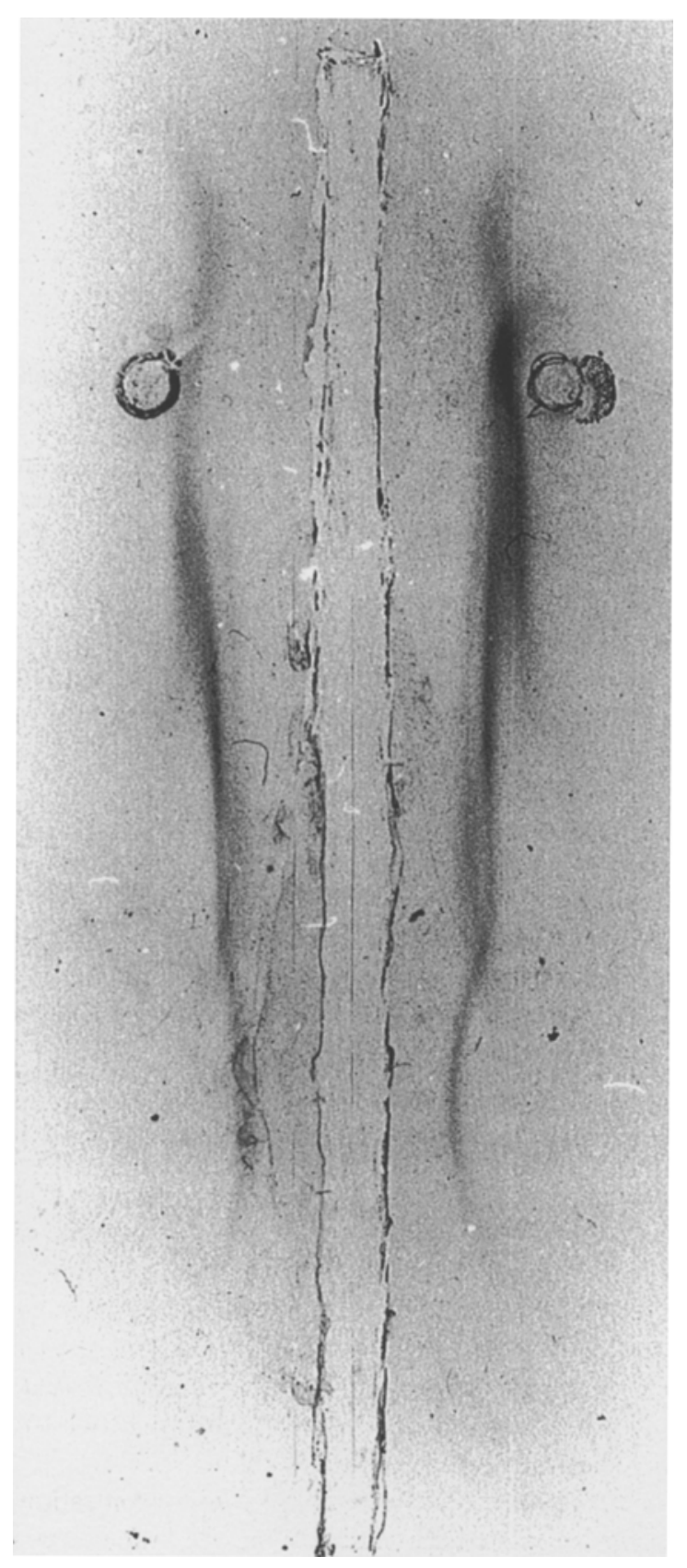

Fig. 1. Immunoelectrophoresis of $B$. fragilis lipopolysaccharide (LPS) before and after ultrafiltration. Left: LPS before ultrafiltration, right: LPS in the residue after ultrafiltration through a $5000 \mathrm{D}$ filter, middle: $B$. fragilis antiserum.

trophoresis of the residue after ultrafiltration through the $5000 \mathrm{D}$ filter, and of the original LPS-solution.

The residue still contains all components of the heterogenous LPS-fraction, and the filtrate did not react with a visible precipitate. CIE with this filtrate was also negative, in contrast to the reaction of the filtrate obtained through the $10000 \mathrm{D}$ filter, in which a small quantity of LPS could be detected. Filtration of an LPS-solution in amniotic fluid through a 5000 D-filter gave quantitative results as shown for one example in Table 2.

The LPS-concentration in the residue was calculated from the final titer in a CIE-test, compared with the titer of the original, unfiltered solution.

The sensitivity threshold of CIE, after tenfold concentration of the antigen solution by ultrafiltration, was determined as $40 \mathrm{ng} \mathrm{LPS} / \mathrm{ml}$ amniotic fluid (antibody source rabbit-anti $B$. fragilis antiserum) and $2 \mathrm{ng}$ LPS/ml (antibody source IgG).

\section{Discussion}

Detection of endotoxins in amniotic fluid by CIE has not yet been described. In connection with intrauterine infections, endotoxins were mainly detected by the limulus amebocyte lysate assay, which is very sensitive, but does not permit identification of the endotoxin. The sensitivity reached by combining ultrafiltration of lipopolysaccharides with CIE is of the same order of magnitude as that described for the detection of capsular polysaccharides by CIE in other body fluids, but lower than the sensitivity of the limulus assay.

For the ultrafiltration of a lipopolysaccharide the molecular weight of the concentrated substance must be known and the pore size of the filter membrane should be carefully adjusted. Although the molecular weight of B. fragilis LPS of 12000 D (Kasper \& Seiler 1975) was above the indicated limit of the $10000 \mathrm{D}$ filter, antigenic components were present in the filtrate, which made the use of a filter with a smaller pore size necessary.

The CIE results obtained with different batches of anti $B$. fragilis antiserum and $\operatorname{IgG}$ indicate that the sensitivity depends heavily on the antibody source. With a highly reactive IgG-preparation, the sensitivity was almost tenfold increased and, in combination with ultrafiltration, reached a detection limit of $2 \mathrm{ng} / \mathrm{ml}$.

The method as described in this report is useful for the specific detection of small quantities of endotoxins in amniotic fluid. 
Table 2. Concentration of $B$. fragilis LPS in amniotic fluid by ultrafiltration through a 5000D-filter.

\begin{tabular}{|c|c|c|c|c|c|c|}
\hline Applied & in & Filtrate & Residue & Theoretic concentration in residue & Detect & $\mathrm{CIE}$ \\
\hline$\mu \mathrm{g}$ LPS & $\mu \mathrm{l}$ & $\mu 1$ & $\mu \mathrm{l}$ & $\mu \mathrm{g} / \mathrm{ml}$ & $\mu \mathrm{g} / \mathrm{ml}$ & (\%) \\
\hline 1.25 & 1000 & 920 & 60 & 21 & 20 & 95 \\
\hline
\end{tabular}

\section{References}

Beckmann I, Meisel-Mikołajczyk F, Leszczynski P \& Wallenburg HCS (1991) Immune response to endotoxin isolated from $\mathrm{Bac}$ teroides fragilis in the pregnant guinea pig. Int Arch Allergy Appl Immunol 42: 222-226

Beckmann I, van Eijk HG, Meisel-Mikołajczyk F \& Wallenburg HCS (1989) Detection of 2-Keto-3-Deoxyoctonate in endotoxins isolated from six reference strains of the Bacteroides fragilis group. Int J Biochem 21: 661-666

Beckmann I, Paelinck J, Zuijderduijn J, Sawicka-Grzelak A \& Meisel-Mikołajczyk F (1985) Immunochemical investigations of antigens isolated from Bacteroides ovatus strain ATCC 8483. Antonie van Leeuwenhoek 51:263-273

El-Refaie M \& Dulake C (1975) Counter-current immunoelectrophoresis for the diagnosis of pneumococcal chest infection. $\mathrm{J}$ Clin Path 28: 801-806

Ericsson CH, Hallander HO, Rosen A, Sjógren AM \& Sjôgren I (1986) Routine use of counterimmunoelectrophoresis for the detection of pneumococcal antigen in sputum. Med Microbiol Immunol 175: 241-249

Granoff DM, Congeni B, Baker R, Ogra P \& Nankervis GA (1977) Countercurrentimmunoelectrophoresis in the diagnosis of Haemophilus influenzae type b infection: Relationship of detection of capsular antigen to age, antibody response, and therapy. Am J Dis Child 131: 1357-1362

Ingram DL, Anderson P \& Smith DH (1972) Countercurrent immunoelectrophoresis in the diagnosis of systemic diseases caused by Haemophilus influenzae type b. J Pediatr 81: 1156-1159
Jacobs RF, Yamauchi T \& Eisenach KD (1981) Detection of Streptococcal antigen by counterimmunoelectrophoresis. Am J Clin Pathol 75: 203-208

Kasper DL \& Seiler MW (1975) Immunochemical characterization of the outer membrane complex of Bacteroides fragilis subspecies fragilis. J Inf Dis 132: 440-450

McKinney MM \& Parkinson A (1987) A simple, nonchromatographic procedure to purify immunoglobulins from serum and ascites fluid. J Immunol Meth 96: 271-278

Meisel-Mikołajczyk F \& Grzelak-Puczyǹska I (1981) Rapid serotyping of bacteria of the Bacteroides fragilis group by direct immunofluorescence serotype specific conjugates. J Appl Bacteriol 51: 393-398

Powell KR, Kaplan SB, Hall CB, Nasello MA \& Roghmann KJ (1988) Periorbital cellulitis: Clinical and laboratory findings in 146 episodes, including tear countercurrent immunoelectrophoresis in 89 episodes. Am J Dis Child 142: 853-857

Shackelford PG, Campbell J \& Feigin RD (1974) Countercurrent immunoelectrophoresis in the evaluation of childhood infections. J Pediatr 85: 405-411

Shetty NP, Srinivasa H \& Bhat $P$ (1985) Coagglutination and counter immunoelectrophoresis in the rapid diagnosis of typhoid fever. Am J Clin Pathol 84: 80-84

Weeke B (1973) General remarks on principles, equipment, reagents and procedures. In: Axelsen NH, Kroll J \& Weeke B (Eds) A Manual of Quantitative Immunoelectrophoresis, Methods and Applications (pp 15-35) Universitetsforlaget, Oslo 